\section{La representación de la paternidad en series de televisión chilenas del siglo XXI \\ Javier Mateos-Pérez ${ }^{\star}$ y Gloria Ochoa Sotomayor **}

Resumen: La televisión chilena en la última década ha conocido un nuevo fenómeno: la producción y emisión de series de ficción nacionales que se han destacado por la audiencia lograda, por la valoración positiva de la crítica, por el debate social que suscitaron, por los contenidos que abordan o por ser un producto innovador y particular. Tal es el caso de Los 80, Minero, No, la serie, Bala loca y Mary\&Mike que, entre otras, son producciones representativas de este hecho.

Estas series desarrollan contenidos críticos vinculados a la historia reciente del país. En particular, respecto a la dictadura militar implantada a partir del 11 de septiembre de 1973, y sus huellas en la actualidad. Al mismo tiempo, a través de ellas se puede reflexionar respecto a otras temáticas, como la representación de género. En cada una de las series indicadas los personajes de los padres son protagonistas y adquieren características particulares que permiten preguntarse por la construcción de masculinidad que hay en ellas. La investigación se plantea desde un enfoque descriptivo-interpretativo y una metodología cualitativa (Valles, 1999), puesto que permite conocer de manera integral fenómenos televisivos complejos (Casetti\&DiChio, 1999). Se propone un análisis narratológico (Aumont\&Marie, 2009) y de representación de género con el fin de indagar en la forma en que las opciones de relato se articulan con determinadas representaciones de ser padre y de masculinidad, las que se dinamizan, actualizan y contextualizan según las características propias de cada serie y su contenido.

De esta forma, se aborda la representación de la paternidad en las seis series señaladas, con la intención de aportar a la discusión sobre representación de género en la producción audiovisual y al estudio de las series de televisión en Chile.

Palabras clave: series televisión - ficción - Chile - masculinidad - paternidad

[Resúmenes en inglés y portugués en las páginas 63 - 64]

${ }^{(*)}$ Doctor en Comunicación Social por la Universidad Complutense de Madrid, profesor Asociado y director de Investigación en el Instituto de la Comunicación e Imagen de la Universidad de Chile. Es editor de la revista académica Comunicación y Medios y forma parte del grupo de investigación de Estudios Avanzados sobre Televisión de la Universidad de Chile. Es co-autor del libro: Chile en las series de televisión: Los 80, Los archivos del Cardenal y El reemplazante (RiL, 2018). 
${ }^{(*)}$ Directora de Germina, conocimiento para la acción, Antropóloga Social y Magíster en Gestión y Políticas Públicas por la Universidad de Chile. Co-autora, entre otras publicaciones, de los libros La persistencia de la memoria. Londres 38, un espacio de memorias en construcción (2011), Yo soy... Mujeres Familiares de Detenidos Desparecidos y Ejecutados de Paine (2014), y Chile en las series de televisión: Los 80, Los archivos del Cardenal y El reemplazante (RiL, 2018).

\section{Introducción y metodología}

Desde finales de la década de 1990 la televisión ha vivido un proceso de cambio propiciado por las tecnologías que han alterado sus formas de distribución, de consumo y que han transformado sus contenidos. La nueva programación ha evolucionado todos los géneros televisivos, incluidas las series de televisión. Estas producciones audiovisuales se han convertido en un referente de las programaciones de la televisión del siglo XXI, tanto de señal abierta, como de pago. Los canales premium y las plataformas de video bajo demanda, han considerado las series como uno de sus productos estrella. Producciones estadounidenses como The Sopranos (HBO, 1999-2007); The Wire (2002-2008); Mad Men (AMC, 20072015) o Breaking Bad (AMC, 2008-2013) ampliaron los contenidos y el valor artístico de las series y cada vez fueron más apreciadas por el público y la crítica, lo que supuso la producción masiva de este género televisivo.

Esta tendencia se extendió por todo el mundo occidental y acabó permeando también en Chile. Desde la mitad del primer decenio del presente siglo se ha producido en este país un auge en la producción de series de televisión de contenido dramático que han logrado importantes resultados de audiencia y posicionarse en lugares privilegiados de la programación. Lo significativo es que, buena parte de estas producciones, que se han realizado en todo tipo de géneros y formatos con aporte estatal para su financiación, se inspiraron en historias y personajes reales, o construyendo sus argumentos sobre momentos relevantes del pasado reciente del país o de sus consecuencias en el presente.

Series como Los 80 (Canal 13, 2008-2014), Minero (ATV, 2013), No, la serie (TVN, 2014), Bala loca (CHV, 2016) y Mary \& Mike (CHV, 2018), entre otras, son producciones representativas de este fenómeno ya sea por su formato, por la audiencia lograda, por la valoración positiva de la crítica, por el debate social que suscitaron, por los contenidos que abordan o por ser un producto innovador y particular. Estas series desarrollan contenidos críticos vinculados a la historia reciente del país. En especial, respecto a la dictadura militar implantada a partir del 11 de septiembre de 1973 (Los 80, No, la serie y Mary \& Mike), y sus huellas en la actualidad (Minero y Bala loca). Al mismo tiempo, a través de ellas se puede reflexionar respecto a otras temáticas, como la representación de género. En cada una de las series indicadas los protagonistas son padres, y el ejercicio de su paternidad juega un rol relevante en la historia y en las tramas que en ellas se presentan. Esto lleva, a que cada personaje paterno adquiera características particulares que permiten preguntarse por la construcción de la paternidad y masculinidad que hay en ellas. 
Respecto a la historia reciente, las narrativas que han empleado estas producciones para contar estas historias han sido fundamentalmente dos. De una parte, la acción de la serie se ha situado en el pasado, recreado mediante una ambientación cuidada, ofreciendo un contexto de la época. De otra, la opción ha sido contar el pasado reciente desde el presente, dando cuenta de consecuencias, efectos o secuelas de éste que aún se mantienen o que condicionan a la sociedad chilena actual. En cuanto a la paternidad, se han representado padres tradicionales que ejercen su paternidad en un modelo patriarcal de familia y que son una figura presente para sus hijos e hijas (Los 80). Otros que, en ese mismo modelo familiar, constituyen una figura ausente (Minero y Mary \& Mike) con escasa interacción en la cotidianidad de su descendencia. Además, encontramos padres que, dada la separación de la pareja -a veces por el propio contexto político en que se sitúa la serie-, ejercen la paternidad asumiendo directamente la crianza de su hijo (No, la serie) o se han distanciado y tratan de recuperar el tiempo perdido debido a la lejanía establecida por diferentes circunstancias (Bala loca).

De esta forma, en este artículo se aborda la representación de la paternidad con la intención de aportar a la discusión sobre la representación de género en la producción audiovisual y al estudio de las series de televisión en Chile. Para ello se realizó un análisis narrativo con el foco de atención en el análisis de género de los personajes masculinos protagónicos, en los temas y en las tramas que los involucran.

Con ese fin, la investigación se planteó desde un enfoque interpretativo y una metodología cualitativa (Valles, 1999). Dicha opción se asume por la pertinencia que ofrece este tipo de estudios para conocer en profundidad y de manera integral fenómenos sociales complejos, como los significados y representación de género contenidos en los relatos televisivos estudiados (Casetti\&DiChio, 1999).

El objeto de investigación fueron las series de televisión, de producción chilena de la última década, donde el padre fuera protagonista del relato. Se procedió al visionado completo de las cinco series seleccionadas: siete temporadas (76 capítulos) de Los 80 (2008-2014); una temporada (11 capítulos) de Minero (2013); (4 capítulos) de No, la serie (2014); una temporada (10 capítulos) de Bala loca (2016) y una temporada (6 capítulos) de Mary \& Mike (2018).

En un segundo visionado se realizó un análisis del relato (Aumont\&Marie, 2009, p.130) y de la narración (Casetti\&DiChio, 2014) de cada serie. Este análisis consistió en reconocer los principales temas que se suscitan en el argumento y en la selección, tanto del personaje que sustenta el eje dramático, como de la trama fundamental. Después se relacionaron los temas y los personajes seleccionados con el ambiente donde discurre la acción. Posteriormente, se ponderó la influencia de la categoría paternidad y se relacionó con la historia que plantea el relato, así como con el personaje protagonista y se procedió a establecer el género en el que cada una de las series se encuentra en función de su trama principal. Por último, se realizó la identificación de los arquetipos con los que se construyeron los personajes articuladores del relato y se analizó la representación de género centrado en la representación de lo masculino a través de la paternidad, en cada una de las series. 


\section{Tema, género y narración de las series}

El enfoque temático posee una destacada presencia institucional. El concepto de tema avala una profusión de investigaciones en la ficción. No hay contenido que se halle al margen de la forma a través de la cual se expresa. La idea de una interacción entre la forma y el contenido podemos encontrarla en teóricos del cine, (Bazin, 2008); Metz, 1970) que sostienen que el correcto estudio de un texto audiovisual supone necesariamente el estudio de la forma de su contenido (Metz, 2002).

En las series de televisión, para definir el género es necesario localizar previamente el significado de su temática, que emplea elementos de reconocimiento de lo que se entiende por género. Los géneros son los grandes grupos en que pueden clasificarse los programas en función de su contenido temático o de la audiencia a la que se dirigen (Barroso, en Guerrero, 2010).

En el caso de la narración, esta es una concatenación de situaciones, en la que tienen lugar acontecimientos y en la que operan personajes situados en ambientes específicos (Casetti\&DiChio, 2014, p.154). Esta definición contempla tres elementos básicos del análisis narrativo: 1) Ocurren acontecimientos. 2) Los acontecimientos se refieren a personajes que se encuentran en un ambiente. Y, 3) Los acontecimientos transforman la situación. El objetivo es entender que el contenido del texto audiovisual no constituye un resultado inmediato, sino que debe construirse (Aumont\&Marie, 2009, pp.131-134).

\subsection{Los 80}

Los Herrera López son la familia de Los 80. Una familia clásica compuesta por un padre, una madre y sus cuatro hijos (dos mujeres y dos varones). La serie se construye a partir de la premisa de observar las experiencias de una familia promedio, de clase media, que vive en el contexto adverso de la dictadura cívico-militar durante la década de los ochenta. El género de Los 80 es el dramedia ${ }^{1}$ (García de Castro, 2002:123), porque combina tramas dramáticas, que aluden a la realidad social y política del periodo, con otras cómicas, habituales en las comedias familiares, que permiten alivianar la carga dramática. Esto ayuda a conectar la serie a realidad y permite utilizar historias próximas y cotidianas, sin final aparente, conocidas y universales.

A pesar de que la serie propone un protagonista colectivo, la familia, el peso narrativo recae en el patriarca. Juan Herrera (Daniel Muñoz) es tradicionalista y está caracterizado como un padre comprometido y un marido aceptable que se enfrenta a un cambio vital consecuencia de las transformaciones económicas, políticas y sociales del país. Su rol de padre es decisivo en el relato, porque los cambios políticos atraviesan a un hogar complejo, que amenaza cada día con ser más disperso y articula nuevas relaciones con su esposa, sus hijos y sus allegados. La paternidad aglutina varias tramas en las que involucra a distintos personajes produciendo cambios en Juan Herrera y se relaciona con la trama principal transversal a las temporadas: la relación, en continua tensión, entre la pareja protagonista. 


\subsection{Minero}

Cuenta la vida de Germain Santana (Daniel Antivilo), un pirquinero de Antofagasta que conduce un taxi cuando no se encuentra en el pirquén, como una estrategia para aumentar sus ingresos económicos y una excusa para estar fuera de casa. Santana lleva una vida caótica y desordenada debido a las jornadas laborales arduas y extensas que realiza y que terminan por afectar a sus relaciones personales.

La representación de la paternidad en la narrativa de la serie es central y se proyecta frente a dos de las tramas principales del relato. Una alude a la relación que mantiene con su esposa y su hija, quienes le exigen mejores condiciones de vida y una mayor dedicación para con ellas; y la otra tiene que ver con la relación que establece con su hijo no reconocido, que viene del sur buscándole para reclamarle por su abandono.

Bajo esta aproximación, Minero se encuadra en el género del drama social, al proponer una reflexión sobre la conciliación familiar en el contexto minero. En este sentido, Santana se presenta como víctima de las abusivas condiciones laborales en este sector productivo. Así, la serie también puede leerse como un alegato que busca reivindicar los derechos de los trabajadores. Con este fin se explica el funcionamiento del negocio, el poder que detentan las grandes empresas mineras, así como el desarrollo e influencia del movimiento sindical de la región.

La serie, por tanto, considera un tema cardinal en la realidad chilena. La minería es la principal actividad de la economía del país y la que convoca la mayor inversión extranjera. El tema minero se despliega contando distintos ángulos: la situación laboral de los trabajadores humildes e independientes en un mundo regido por las mineras transnacionales. Además, se cuentan otros temas secundarios, como el machismo, el abandono paterno, las relaciones paternofiliales, el alcoholismo, el maltrato policial, la prostitución, el sindicalismo, los abusos de poder o la explotación de las riquezas naturales del país.

\subsection{No, la serie}

Esta miniserie es una adaptación extendida de la película homónima de Pablo Larraín (2012), que a su vez está basada en la obra de teatro El Plebiscito, de Antonio Skármeta². La historia se centra en la campaña electoral del plebiscito nacional que convocó la dictadura en 1988, con el objeto de decidir entre la continuidad de Augusto Pinochet -SI- o convocar elecciones que abrieran el camino a la transición a la democracia-NO-.

El protagonista es René Saavedra (Gael García), un publicista talentoso, retornado del exilio en México que, con algunas dudas iniciales, se alista al equipo creativo a cargo de la campaña televisiva para la Concertación de Partidos por el $\mathrm{No}^{3}$. René propone un enfoque innovador, moderno y comercial basado en el optimismo y la felicidad. Este planteamiento choca con la visión de la madre su hijo, una opositora que cree que la votación está amañada; con el propio subcomité de publicidad, que estima que el mensaje del video promocional es vacuo, heterodoxo e irrespetuoso con las víctimas de la dictadura; con su jefe en la agencia de publicidad, que integra el bando contrario y le torpedea con ofertas y chantajes; y con el propio gobierno dictatorial, que trata de interferir a su favor en la campaña mediante censuras, amenazas, coacciones, intimidaciones y ataques policiales. 
La paternidad juega en este relato un papel importante. Para René, su hijo Simón (Pascal Montero) es lo más valioso de su vida. Pasa todo el tiempo posible con él, tanto en sus momentos de ocio como en el trabajo, hasta el punto de que el niño se convierte en un apéndice suyo. Todos los obstáculos que René encuentra en su camino profesional los sortea con relativa facilidad hasta que amenazan a su hijo por su desempeño en la campaña y esto lo altera y lo sobrecoge. Además, Simón es la única esperanza que tiene de recuperar a Verónica (Antonia Zegers), a pesar de que ella le rechaza por el concepto vital antagónico que siente. Cuando gana la opción del NO, René y su hijo recorren las celebraciones sin integrarse en ellas, observándolas en silencio, y solo al final, cuando festejan juntos el triunfo, en solitario, disfrutando de un viaje íntimo en una atracción de un parque de diversiones, aparecen las sonrisas en sus caras.

No, la serie se sitúa en el género dramático. Aborda desde la perspectiva publicitaria el triunfo del NO en el plebiscito nacional de 1988, un hito fundamental de la historia reciente del país. No en vano, este acontecimiento significó el final de la dictadura y el inicio de una nueva etapa conocida como la transición a la democracia. En el relato se abordan temas secundarios que aluden a: la publicidad, la dictadura, la política chilena y la identidad nacional.

\subsection{Bala loca}

Es la historia de Mauro Murillo (Alejandro Goic), un popular periodista en situación de discapacidad que fue opositor al régimen dictatorial y que en el presente trabaja como tertuliano en programas nocturnos de espectáculos. La crisis profesional por la que atraviesa, consecuencia de su transvase de periodista a personaje de farándula, se amplifica con la crisis personal que arrastra: separado, con un hijo al que no ve y una novia insatisfecha. Su redención pasa por emplear las ganancias económicas generadas en la televisión en fundar un portal digital informativo bajo el enfoque del periodismo de investigación. Para ello recurre a Patricia Fuenzalida (Catalina Saavedra), una antigua compañera de oficio, que trabaja en un blog independiente desde donde denuncia corrupciones económicas y políticas del país. Cuando Murillo trata de convencerla para que se una al proyecto, ésta es asesinada, en extrañas circunstancias, por una bala loca mientras compraba en un supermercado.

Este acontecimiento redobla el esfuerzo de Murillo y crea el periódico en línea En Guardia, para el que se rodea con periodistas comprometidos con la calidad en el ejercicio de su profesión, la justicia y la verdad. Todo el equipo se verá envuelto en una investigación que conecta la muerte de Fuenzalida con distintos poderes fácticos -medios de comunicación, empresarios, políticos, militares- que tratarán de obstaculizar el trabajo del nuevo periódico. Su papel como padre contribuye en la narrativa como agente en la transformación personal del protagonista. Acercarse a su hijo y comprenderlo le sirve para recomponerse y poner orden en sus relaciones personales.

La serie transita entre el género dramático y el de suspense. La profesión del protagonista ayuda a ahondar en diferentes temas que afectan al país, como la corrupción empresarial y de las instituciones públicas. Aparecen otros tópicos vinculados tanto a conflictos personales como de la sociedad chilena: homosexualidad, infidelidad, relaciones parentales, integración de discapacitados, violaciones de derechos humanos y adicción a las drogas. 


\subsection{Mary \& Mike}

Esta miniserie cuenta la historia de la pareja formada por la escritora chilena Mariana Callejas (Mariana Loyola) y el ex agente de la CIA Michel Townley (Andrés Rillón), cuando ambos fueron reclutados como colaboradores de la Dirección de Inteligencia Nacional (DINA) en la década de 1970, durante la dictadura dirigida por Augusto Pinochet.

El matrimonio participó en varias operaciones destinadas a la eliminación de grupos y personas que se opusieron a la dictadura. Por ejemplo, el asesinato de Carlos Prats, ministro y vicepresidente de Allende, y su esposa Sofía Cuthbert, en Buenos Aires (1974); el tiroteo contra Bernardo Leighton, opositor a la dictadura, y su esposa Ana María Fresno, en Roma (1975); o el atentado con coche bomba que le costó la vida a Orlando Letelier, ex Canciller del gobierno de la Unidad popular, y a su secretaria Ronni Moffitt, en Washington (1976).

Con afán de que pasaran inadvertidos, la policía secreta de la dictadura les pagó una casa en Lo Curro, uno de los barrios más exclusivos de Santiago. Allí desarrollaban una doble vida. Mientras en la primera planta Mary celebraba un taller de escritura con personas destacadas del mundo literario, o sus hijos jugaban en los jardines con compañeros de clase, en el sótano se instalaba el cuartel Quetropillán, donde Townley integraba un comando que planeaba atentados, armaba explosivos, falsificaba pasaportes, experimentaba con gas sarín o torturaba a opositores al régimen.

Precisamente, la paternidad en este relato se emplea para enfatizar, por un lado, la apariencia de normalidad que buscaban para ocultar sus actividades como terroristas de Estado, y por otro, sirve para reseñar la falta de humanidad del protagonista: un progenitor frío, ambicioso, necesitado de reconocimiento y más interesado en el fanatismo político que en sus propios vástagos.

La serie se inscribe en el género dramático thriller y trabaja como tema principal el terrorismo de Estado perpetrado por la dictadura chilena. Se trata de un relato real y documentado, tanto por investigaciones periodísticas como judiciales. Se apuntan una serie de contenidos secundarios como la ambición, la infidelidad, el espionaje o el abuso infantil.

\section{Representación de género: la masculinidad a través del padre}

Los estudios relativos a la industria cultural no han estado ajenos a la reflexión en torno a la representación del género en la televisión, aunque se han centrado principalmente en la forma en que se representa a las mujeres y lo femenino en distintos productos audiovisuales (Sangro\&Plaza, 2010; Coronado\&Galán, 2015). Así, por ejemplo, se encuentran investigaciones respecto a la invisibilización y/o caracterización estereotípica de las mujeres (Menéndez\&Zurian, 2014), los estereotipos de representación masculina (Menéndez\&Zurián, 2014) y femenina (Guarinos, 2011), incluso la representación de nuevas identidades en las series de ficción (Cobo, 2011).

De esta manera, los estudios sobre la representación de género apuntan a que la ficción televisiva ha seguido los cánones establecidos por la representación del orden patriarcal (Ortega\&Simelio, 2010), con inclusión de los cambios sociales ocurridos en la sociedad actual (García, Fedele\&Gómez, 2012). Por ello, conciben la ficción televisiva como vehi- 
culadora de formas de representación de mujeres y hombres (a través de estereotipos de género) y también de nuevas identidades de género (por medio de diversas expresiones de lo masculino y femenino distinto al imperativo patriarcal). En este sentido, en ningún caso ajena, indiferente o neutral a estas consideraciones (Belmonte\&Guillamón, 2008).

Respecto a la representación de la paternidad, esta juega un papel en la narrativa de las series de televisión. En sus inicios primó una perspectiva idealista de ésta a través de un "pater familias casi omnisciente, que sabía lo mejor para todos y que se caracterizaba por ser justo a la par que cariñoso, por su autoridad indiscutible y, sobre todo, por la relación jerárquica de dependencia en cualquier ámbito de los hijos hacia el padre" (Crisóstomo, 2015:1). Esta representación habría mutado a una donde las relaciones de conflicto entre padres e hijos resultaron ser un eje articulador de las narrativas como una fuente inagotable de tensión. Sin embargo, siguiendo a Crisóstomo, se evidencia en la nueva ficción seriada un cambio de paradigma donde las relaciones entre padres e hijos-hijas dejan de ser problemáticas para convertirse en relaciones de colegas o compañeros, lo que ocurre tanto con la figura del padre como de la madre.

Bajo este concepto, la autora distingue, en las llamadas series de la tercera edad de oro ${ }^{4}$, tres tendencias de representación de la paternidad-maternidad: a) la trágica; b) el legado de los padres a los hijos; y, c) la del "progenitor colega". La primera se refiere a que la paternidad-maternidad ejerce un amplio poder sobre los hijos, no se puede ignorar y les coarta a tomar decisiones libremente. La segunda retrata la tendencia a perpetuar el legado de un progenitor, generalmente dedicado a un bien mayor, como ocurre en el caso de los superhéroes. El legado no siempre es explícito y puede actuar como un determinismo implícito. La tercera describe relaciones paternofiliales de "igual a igual" donde los hijos o hijas ayudan a sus padres-madres a tomar decisiones vitales, o se transforman en sus cuidadores. Esto no significa que se evidencien problemas de madurez en las o los progenitores, sino que justamente se trata de que ambas partes presentan madurez emocional. Si bien en las series chilenas analizadas no necesariamente encontramos la clasificación que realiza la autora, sí observamos a los padres y la paternidad como ejes significativos de la narrativa y como motivadores del relato. Lo que resulta particularmente interesante cuando uno de los planteamientos respecto a la identidad chilena ha sido que se encuentra definida por su carácter "huacho" (Montecino, 2017), es decir, por hijas e hijos en conflicto por la ausencia, no reconocimiento o abandono de parte del padre. De esta forma, estas series muestran un matiz identitario donde la figura del padre resulta central y encontramos esta figura en tránsito y como manifestación de diferentes expresiones de masculinidad. En general, para estos padres -Juan, Germain, René y Mauro- la paternidad es un punto de tensión entre su propia realización personal y la responsabilidad que la paternidad impli$\mathrm{ca}$, que se resuelve de diferentes maneras. En algunos de ellos, la forma en que esa tensión se enfrenta responde a la relación -a su vez- que estos padres tuvieron con sus progenitores, particularmente en la historia de Juan, Germain y Mauro. Así como con su capacidad de adaptación a un nuevo contexto y momento vital, tanto de estos protagonistas como de sus hijos. Mike es un caso particular, porque si bien vive y se relaciona cotidianamente con sus hijos, sus motivaciones e intereses no se encuentran anclados en su paternidad, sino en sus deseos de colaborar con los aparatos represivos y legitimarse ante sus líderes. Juan, de la serie Los 80 , es un padre que inicialmente responde al pater familias omni- 
presente, protector y que resuelve todos los contratiempos que enfrenta la familia. Esto lo afecta profundamente, puesto que, con los cambios políticos, sociales y económicos propiciados por la dictadura, no puede ejercer ese rol y debe adaptarse a que Ana (Tamara Acosta), su esposa, trabaje fuera del hogar para complementar el ingreso familiar, Claudia (Loreto Aravena), la hija, se vaya del hogar para seguir sus ideales políticos, y se tensione todo el núcleo familiar hasta la separación del matrimonio. Esto lleva a que la figura del padre de Juan se haga presente en su vida contrariándole, puesto que este hijo siempre quiso ser lo contrario de su padre: un padre presente y protector versus el padre ausente y sin referente que fue su propio progenitor. Por lo tanto, el contexto y el devenir de la familia y sus miembros, tensiona a Juan entre su proyecto de paternidad, y la posibilidad efectiva de realizarlo como lo proyectó, o tener que adaptarse y flexibilizar su postura pasando de un pater familias tradicional a uno ajustado a los "nuevos tiempos", en los que el rol de padre proveedor en el que se concentran las decisiones familiares, se impacta por los cambios económicos, sociales y políticos producto de la dictadura.

Germain, protagonista de Minero, también se enfrentó en su niñez a la ausencia de la figura paterna, porque su padre falleció trabajando en el pirquén. Este personaje lleva al extremo la ausencia de su progenitor al renunciar a su apellido y usar el de su madre, la que también muere cuando Germain era un niño. Por ello se fue forjando a sí mismo y, de cierta manera, renegando de todo. Al contrario de Juan, no logró revertir en el ejercicio de su propia paternidad ese sino y se convirtió en un padre ausente para Elvira (Tiare Pino), su hija, y Adrián (Camilo Carmona), su hijo. Este padre, de cierta manera, es la encarnación de las expectativas frustradas respecto a un progenitor: no conocía -ni, por tanto, reconoció- la existencia de su hijo mayor, ya que abandonó a la madre; se mantiene ajeno a los hitos significativos de la vida de la hija con la que vive, y nunca fue capaz de acompañar afectivamente su formación, transitando entre la total ausencia de límites a un autoritarismo sin sentido. Germain se enfrenta a una hija adolescente, que no legitima esta autoridad paternal, y a un hijo sin padre que primero la rechaza, pero luego la acepta por la carencia de figura paterna que arrastra. Sin embargo, a pesar de estos antecedentes, la redención de una vida sin sentido de Germain se realiza cuando éste decide apoyar a Elvira y Adrián, haciéndose cargo, a su modo, de enmendar su paternidad ayudándolos a costa de su propia muerte.

En el caso de Bala loca, se presenta a Mauro como un hombre que trata de reinventarse luego de un accidente que cambió radicalmente su vida. Accidente que lo distancia de su vida como un exitoso conductor de programas de farándula. Mauro ve una posibilidad de reivindicar y dar sentido a su existencia fundando un periódico digital dedicado al periodismo de investigación. De esta manera, intenta acercarse a su pasado como periodista de un medio de comunicación opositor a la dictadura que se encargaba de denunciar los atropellos que esta cometía. Parte de esta reivindicación es reconciliarse con su paternidad, de la que estuvo alejado producto de su participación en el mundo televisivo. Para acercarse a Daniel (Víctor Quezada), su hijo, Mauro se posiciona como un par, o un como colega, como lo define Crisóstomo (2015). En esta experiencia acompañará a la madre de su hijo a aceptar la homosexualidad no manifiesta de Daniel y a aprender de él una masculinidad receptiva y acogedora, distinta de la masculinidad superficial basada en la apariencia del mundo del espectáculo. En paralelo, deberá reconciliarse con su progenitor, 
de quien se mantuvo alejado por años debido al resentimiento de éste por haber perdido un hijo bajo la represión dictatorial, desentendiéndose de Mauro o incluso renegando del camino que éste eligió al introducirse en el mundo televisivo.

René, protagonista de No, la serie, es particularmente interesante desde el punto de vista de la representación de la paternidad, porque nos muestra un modelo que es poco habitual en Chile: el padre que se hace cargo del cuidado cotidiano de su hijo, debido a que la madre ha tomado un camino de vida distinto al común. Verónica, la madre del hijo de René, se nos presenta como una opositora radical a la dictadura militar y también al referéndum como posibilidad de derrocar al dictador. Asimismo, tiene una nueva pareja con la que comparte esa posición política y ha decidido abocarse a su militancia desplazando su rol de madre. En este escenario, es René quien ejerce las tareas de cuidado cotidiano de su hijo Simón, auxiliado por una empleada de confianza, ya que al mismo tiempo se encuentra activamente involucrado con su trabajo como publicista y en su labor en la campaña del NO. Aunque Simón es muy joven, se muestra la complicidad entre padre e hijo, puesto que ambos deben enfrentar el abandono: de la madre uno y de la esposa el otro, constituyéndose en compañeros tanto en la vida familiar como en su participación en los acontecimientos que vive el país, tal como lo muestra su presencia en la manifestación previa a la votación y en la celebración del triunfo del NO el día del plebiscito.

Por último, de mayor particularidad resulta la representación de la paternidad de Mike (Mary \& Mike). Aquí se trata de un extranjero en Chile que busca congraciarse con las autoridades dictatoriales demostrándoles su fidelidad al convertirse en agente de los aparatos represivos de la época. Por ello, será central para él cumplir con cada una de las misiones que le encomiendan y que consisten en eliminar a opositores al régimen que se encuentran en el extranjero. Esta fidelidad y necesidad de reconocimiento lo llevan a convertir su propio hogar en una casa de tortura y de experimentación de distintos métodos de aniquilación de cualquiera que se identifique como enemigo. Lo que significará que, mientras sus hijos experimentan una vida común en la casa, él estará torturando bajo distintas modalidades, a opositores al dictador en el subterráneo. Se muestra así una paternidad enajenada de la expectativa de lo que debe ser un padre y alejada de las necesidades de su descendencia, puesto que la focalización en su carrera como agente lo distancia del ejercicio de la paternidad. Al mismo tiempo, en este caso cobra relevancia la figura del propio progenitor de Mike, a quien se asocia como un agente de los órganos de inteligencia estadounidenses, por lo que este hijo pareciera hacerse cargo del legado de su padre en contra del comunismo que amenaza al mundo.

Como podemos ver, la paternidad en estas series se presenta como un contenido complejo, donde ninguno de los padres encarna de manera perfecta o acabada ese rol. Más bien, la paternidad desafía a estos personajes a encontrarse con sus propias y no abordadas experiencias como hijos, y a encontrar en el ejercicio de la paternidad un camino para enfrentar sus temores e inseguridades, y a enfrentar los desafíos del contexto en el que les toca desenvolverse. En este sentido, la paternidad asumida conscientemente significa un camino de autoconocimiento que permite la evolución de estos personajes. $\mathrm{O}$, en el caso de Mike, una total negación, es decir, la ausencia del ejercicio de la paternidad. 
La paternidad, combinada con otras experiencias de vida, se nos presenta como central en estos relatos y tensiona una visión masculina alejada del ámbito doméstico y de cuidado, así como de la identidad de huacho en la representación de lo chileno en estas producciones audiovisuales.

\section{Conclusiones: representación de la paternidad y series de televisión chi- lenas}

De acuerdo a lo expuesto, podemos indicar que la paternidad es un elemento que complejiza la masculinidad y la construcción de identidad de los protagonistas de las series analizadas, puesto que tensiona a los personajes, les entrega matices, a partir de ello toman decisiones de las que no siempre se sienten satisfechos y les otorga sentido a su vida. Todo lo cual, los hace definirse, principalmente, en cuanto padres, predominando sobre otras fuentes de identidad o definición de masculinidad como el trabajo, la participación política, la relación con el grupo de pares o su vínculo con las mujeres, entre otros. No solo por el propio ejercicio de dicha paternidad, sino también por la relación que tuvieron o tienen con sus progenitores. También porque esta justifica la propia existencia -como en el caso de Juan, patriarca por definición- o se utiliza como un medio de reivindicación -como se observa en Germain y Mauro que la usan para dotar de sentido a su vida- por ejemplo.

Así, la relación que estos personajes han vivido con sus progenitores marca tanto su concepto de paternidad como las relaciones que tienen con sus vástagos. Las relaciones paternofiliales que sostienen les lleva a diferentes desencuentros que, en muchos casos, tienen que ver con la falta del referente paterno que han padecido. La llamada 'tensión de la ausencia, es decir, el abandono paterno, se confirma como una característica que se relaciona con la representación de la paternidad en todos estos relatos.

La paternidad se adivina, además, como un área que les señala que viven en un nuevo tiempo y en un momento vital que deben de afrontar y, en algunos casos, superar aprendiendo a ser padres. Sobre todo, porque estos protagonistas se inscriben en la tradición de la paternidad patriarcal: se trata de personas que consideran que ser padre es proveer económicamente a su familia más que ser parte activa de la crianza o acompañar a su progenie en los momentos trascendentes de su vida. La relación que establecen con sus hijos e hijas prioriza la filiación, es decir, reconocer y hacerse cargo oficialmente de ellas y ellos -en tanto descendencia-, dejando en un segundo plano el ámbito afectivo y de acompañamiento.

Una excepción parece en este sentido la paternidad que desarrolla René, aunque cabe preguntarse si su rol en la crianza es más activo debido a la ausencia de la madre del hijo, y si actuaría de la misma forma si ella estuviera involucrada en esa crianza. Es decir ¿el personaje tendría una paternidad activa si la madre ocupara el lugar tradicional que se le asigna en las labores de crianza? O, ¿la participación del padre en el cuidado del hijo es una forma de compensar la ausencia de la madre? También resulta fuera de lo común Mike. En este caso por su extrema enajenación respecto a su rol de padre, su desempeño como agente de la represión ni siquiera le permite sintonizar o empatizar en algún sentido con su hija e hijo. 
La representación de la paternidad en estas producciones audiovisuales de ficción, invita a pensar en los nuevos atributos de masculinidad presentes en la sociedad actual. Esto, porque, a través de esta mirada crítica a la paternidad patriarcal o convencional, se establece un referente de lo que se espera que los hombres hagan en tanto padres. Es decir, la sociedad ha experimentado transformaciones que apuntan a una paternidad más activa, por lo tanto, los hombres se enfrentan a ese referente de construcción de masculinidad en el ejercicio de la paternidad. Lo que significa, entre otras cosas, un compromiso hacia la dimensión reproductiva y de cuidado que tradicionalmente fue atribuida a las mujeres y que se evidencia la paternidad responsable como forma de reivindicación de los personajes que se situaban en una paternidad ausente. Esto, también pone en escena distintas posibilidades de ejercicio de la paternidad y de desarrollo de las relaciones paternofiliales, como las expuestas en estas series que van desde el pater familias por excelencia hasta aquel totalmente alienado de esa experiencia en su vida, como contrapunto a la expectativa del ejercicio de una paternidad comprometida.

\section{Listas de Referencias Bibliográficas}

Aumont, J \& Michel, M. (2009). Análisis del film. Barcelona: Paidós.

Bazin, A. (2008). ¿Qué es el cine? Madrid: Rialp.

Belmonte, J. \& Guillamón, S. (2008). Co-educar la mirada contra los estereotipos de género en TV. Comunicar, 16 (31), 115-120. http://dx.doi. org/10.3916/c31-2008-01-014

Casetti, F. \& Di Chio, F. (2014). Cómo analizar un film. Barcelona: Paidós.

Casetti, F. \& Di Chio, F. (1999). Análisis de la televisión. Instrumentos, métodos y prácticas de investigación. Barcelona: Paidós.

Cobo, S. (2011). "Uso de roles en la construcción de personajes: desde la Nueva Masculinidad a los estereotipos de género en Misfits". In M. Pérez (Coord.), Previously on: interdisciplinary studies on television fiction in the golden age of television (pp. 585-597). Sevilla: Biblioteca de la Facultad de Comunicación de la Universidad de Sevilla. Obtenido de https://dialnet.unirioja.es/servlet/ articulo?codigo=3800806 [Consultado 21 de noviembre 2018].

Coronado, C. \& Galán, E. (2015). “ ¿Tontas y locas? Género y movimientos sociales en la ficción televisiva sobre la transición española. Historia y Comunicación Social”, 20(2), 327-343. Obtenido de http://revistas.ucm.es/index.php/HICS/article/view/51387/47667 [Consultado 21 de noviembre de 2018].

Crisóstomo, R. (2015). "El progenitor "colega". Nuevas relaciones paternofiliales en las series de televisión”. En Padres y madres en serie: representaciones de la parentalidad en la ficción televisiva / coord. por Mariona Visa Barbosa, 2015, ISBN 978-84-9064-381-5, págs. 33-40

García, N., Fedele, M. \& Gómez, X. (2012). "La representación laboral de las mujeres en las series de prime-time”. In Comunicació i Risc: III Congrés Internacional Associació Espanyola d'Investigació de la Comunicació, Tarragona, Spain, p. 123. Obtenido de https://dialnet.unirioja.es/servlet/articulo? codigo=5250989 [Consultado 21 de noviembre de 2018]. 
García de Castro, M. (2002). La ficción televisiva popular. Una evolución de las series de television en España. Barcelona: Gedisa.

Guarinos, V. (2011). "La edad adolescente de la mujer. Estereotipos y prototipos audiovisuales femeninos adolescentes en la propuesta de Disney Channel”. Comunicación y Medios, 23 (2011), 37 - 46. doi:10.5354/0719-1529.2011.26339

Guerrero, E. (2010). El entretenimiento en la televisión española: historia, industria y mercado. Madrid: Deusto.

Menéndez, M. \& Zurian, F. (2014). "Mujeres y hombres en la ficción televisiva norteamericana hoy". Anagramas, 13(25), 55-72. Obtenido de http://revistas.udem.edu.co/index. php/anagramas/article/view/974/976 [Consultado 21 de noviembre de 2018].

Metz, C. (2002). Ensayos sobre la significación en el cine (1964-1968). 2 Vols., Barcelona: Paidós.

Metz, C. (1970). “El decir y lo dicho en el cine: ¿Hacia la caída de un cierto verosímil?” Lo verosímil, pp. 17-30. Buenos Aires: Editorial Tiempo Contemporáneo.

Montecino, S. (2017). Madres y huachos. Alegorías del mestizaje chileno. Santiago de Chile: Editorial Catalonia.

Ortega, M. \& Simelio N. (2010). "La representación de mujeres trabajadoras en series de máxima audiencia”. Comunicación, 10(1), 1006-1016. Obtenido de http://www. revistacomunicacion.org/pdf/n10/mesa5/079.La_representacion_de_las_mujeres_ trabajadoras_en_las_series_de_maxima_audiencia_emitidas\%20en_Espana(2010).pdf [Consultado 21 de noviembre de 2018].

Sangro, P. \& Plaza, J. F. (Eds.). (2010). La representación de las mujeres en el cine y la televisión contemporáneos. Barcelona: Laertes.

Valles, M. (1999). Técnicas cualitativas de investigación social: reflexión metodológica y práctica profesional. Madrid: Síntesis.

Abstract: Chilean television in the last decade has seen a new phenomenon: the production and broadcast of national fiction series that have been highlighted by the audience achieved, by the positive evaluation of the critics, by the social debate that they raised, by the contents that address or for being an innovative and particular product. Such is the case of Los 80, Minero, No, la serie, Bala loca and Marye $r$ Mike that, among others, are productions representative of this fact.

These series develop critical contents linked to the recent history of the country. In particular, with respect to the military dictatorship implemented as of September 11, 1973, and its traces today. At the same time, through them you can reflect on other issues, such as gender representation. In each of the indicated series, the characters of the parents are protagonists and acquire particular characteristics that allow us to wonder about the construction of masculinity that is in them.

The research is based on a descriptive-interpretative approach and a qualitative methodology (Valles, 1999), since it allows comprehensive knowledge of complex television phenomena (Casetti \& DiChio, 1999). We propose a narratological analysis (Aumont\&Marie, 2009) and gender representation in order to investigate the way in which storytelling options are ar- 
ticulated with certain representations of being father and masculinity, which are dynamized, updated and contextualized according to the characteristics of each series and its content. In this way, the representation of paternity in the six aforementioned series is addressed, with the intention of contributing to the discussion on gender representation in audiovisual production and the study of television series in Chile.

Keywords: TV series - fiction - Chile - masculinity and fatherhood.

Resumo: O televisão chilena na última década tem visto um novo fenômeno: a produção e transmissão de série de ficção nacional que tenham sido destacada pelo público atingido pela avaliação positiva do debate social crítica levantada pelo conteúdo endereço ou por ser um produto inovador e particular. Tal é o caso dos 80, Mineração, Não, a série, louco Bala e Mary \& Mike, entre outros, são produções representativos deste fato. Estas séries desenvolvem conteúdos críticos ligados à história recente do país. Em particular, no que diz respeito à ditadura militar implementada a partir de 11 de setembro de 1973 e seus traços hoje. Ao mesmo tempo, através deles, você pode refletir sobre outras questões, como representação de gênero. Em cada uma das séries indicou os caracteres dos pais são atores e têm propriedades que permitem a questionar a construção da masculinidade neles. A investigação surge de uma abordagem descritiva interpretativo e metodologia qualitativa (Valles, 1999), uma vez que permite uma avaliação abrangente do complexo televisão fenômenos (Casetti \& Dichio, 1999). uma análise narratológica (Aumont e Marie, 2009)) é proposta e representação de gênero, a fim de investigar como articular conto opções com certas representações da paternidade e masculinidade, que são revigorados, refrescado e contextualizam de acordo com as características de cada série e seu conteúdo. Assim, a representação da paternidade é abordada na série mencionada seis, com a intenção de contribuir para a discussão sobre a representação de gênero na produção e estudo da série de televisão no Chile audiovisual.

Palavras chave: Séries de TV - ficção - Chile - masculinidade e paternidade.

[Las traducciones de los abstracts fueron supervisadas por el autor de cada artículo] 